\title{
Assessment of heavy metals in modern bottom sediments on the Karadag seashore
}

\author{
Anna Drygval ${ }^{*}$, Polina Drygval ${ }^{2}$, Elena Stanis $^{2}$, and Vladimir Maltsev ${ }^{3}$ \\ ${ }^{1}$ A.O Kovalevsky Institute of Biology of the Southern Seas of RAS, Nakhimov avenue 2, Sevastopol, \\ 299011 \\ ${ }^{2}$ Peoples' Friendship University of Russia (RUDN University), Faculty of Ecology, 6 Miklukho- \\ Maklaya St, Moscow, 117198, Russian Federation \\ ${ }^{3}$ T.I. Vyazemsky Karadag Scientific Station - Nature Reserve of RAS - Branch of A.O. Kovalevsky \\ Institute of Biology of the Southern Seas of RAS, Nauki street 24, Feodosia, Kurortnoye, 298188
}

\begin{abstract}
The work presents the results of quantitative assessment of heavy metals (HM) content in bottom sediments of the coastal zone near the Karadag nature Reserve. The data were obtained as a result of field studies in 2016-2018. Estimated CC and Co coefficients and Zc were calculated. It was shown that arsenic concentration limits were exceeded everywhere in the samples. The nickel, lead, copper and zinc limits were found to have been exceeded in some locations. Ecological and geochemical assessment of water and bottom sediments quality in the section of Karadag water area has been made.
\end{abstract}

\section{Introduction}

Bottom sediments are an integral component of aquatic ecosystems and largely determine the quality of the water layer. The level of different substances in sediments can provide an objective view of the aquatic ecosystems stagehand and also determine the source of input of a substance into the water area. With negligible surface runoff from the area, most solid runoff accumulates in a fairly narrow coastal zone. Substances dissolved in the surface runoff of continental waters also enter there. The finely dispersed part of the bottom sediments is a good adsorbent and deposit medium for various elements. At the same time, such sediments themselves become sources of secondary pollution of the bottom water layer and substrate on which coastal organisms live [3]. This means that sediments are included in the food chain of bottom organisms. It is known that a feature of heavy metals is their ability to accumulate in bottom sediments, becoming a potential source of secondary contamination of water mass under certain conditions.

The aim of the study is to conduct an environmental-geochemical assessment of the modern sediments quality in a narrow coastal area near the Karadag natural reserve in terms of heavy metals content.

\footnotetext{
*drygval95@imbr-ras.ru
} 


\section{Objects and methods of research}

The study area is situated on the shoreline of the Sudak-Karadag lowland [5]. From a geological point of view, the bedding coastal rocks belong to the terrigenous flisch and flishlike sediments of the Triassic-Jurassic period and various volcanogenic rocks represented by rhyolites, rhyolite-dacites, dacites, andesite-dacites, andesite, andesitebasalts, basalts [4]. Quaternary sediments are represented mainly by the eluvia of native rocks.

Expeditionary studies consisted in sampling sediment along the route from Lis'ya bay to Kiik-Atlama Cape. The points of selection are shown in the diagram (Figure 1).

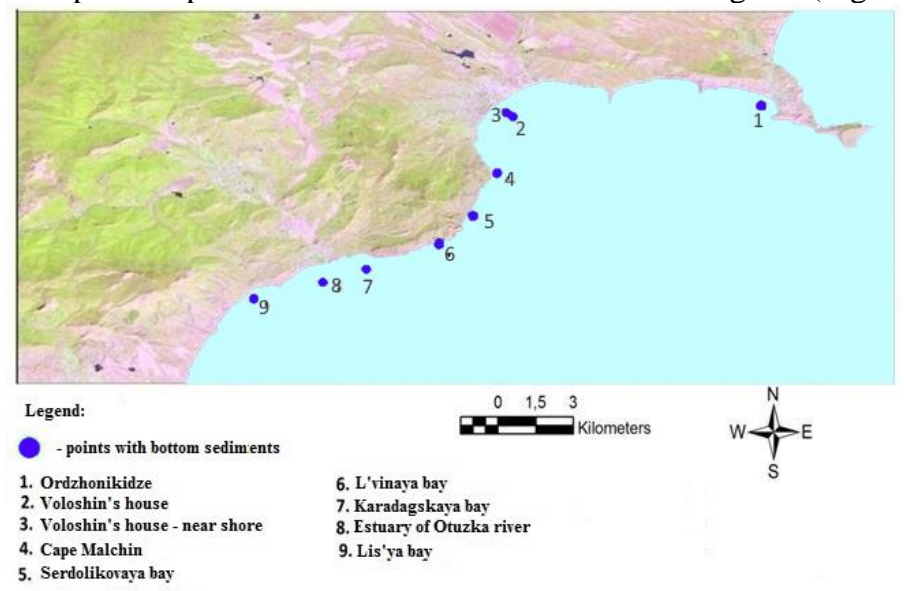

Fig. 1. Sampling points in the narrow coastal area of the Karadag seashore

Expeditionary studies consisted of sampling bottom sediment along the route from Lis'ya Bay to Kiik-Atlama Cape. The procedure of sampling, processing and analysis was in line with the accepted methodology [1].

The total HM content was determined by X-ray fluorescence analysis using a sequential wave-dispersion S4 PIONEER spectrometer. The analysis of bottom sediments was carried out on the basis of the laboratory of chemical and analytical studies of the GIN RAS.

Further assessment of the results obtained was made using several approaches, since at the moment there is no generally accepted methodology for assessing bottom sediments.. One of the approaches is a method based on grading the multiplicity of excess of the assessed substances content in relation to the quality parameters of bottom sediments. In the work such excesses have been calculated using the concentration coefficient (CC) - the ratio of the chemical element content in bottom sediments to the clark of this element. The values of the earth's crust element clarks by A.P.Vinogradov were used [6].

The application of earth's crust element clarks is the most common approach to assessing the environmental-geochemical condition of bottom sediments, since the geological features and presence of different genesis rocks and specific soils in the study areas affect the average content of chemical elements in bottom sediments. In our study, the excess of local concentrations over clarke concentrations will reflect local geochemical features for these elements in the bottom sediments. of the studied area.

The second approach in environmental-geochemical assessment of bottom sediments is related to the use of the regional standard for St. Petersburg [2]. This document is an innovation for Russian practice. The norms and criteria in this document have been established within the framework of Russian-Dutch cooperation (PSO 95/RF/3/1 programme), based on criteria already developed by the Dutch Environmental Protection Agency (DCMR). In general, this standard is based on a comparison of heavy metal content 
in bottom sediments with $\mathrm{APC}_{0}$ (this is an approximate permissible concentration below which the bottom sediments are treated as pure). On the basis of these limit concentrations, a coefficient $\mathrm{Co}$ (the ratio of the chemical element in bottom sediments to $\mathrm{APC}_{0}$ for the element) has been calculated.

For further assessment of the contamination level of bottom sediments we used the total pollution index Zc [7], based on comparison with MAC or APC of pollutants in soils:

$$
Z_{C}=\sum\left(\frac{[M e]}{A P C_{0}}-1\right)
$$

where $[\mathrm{Me}]$ is the concentration of metals, in $\mathrm{mg} / \mathrm{kg}$;

(1)

$\mathrm{APC}_{0}$-an approximate permissible concentration below which the bottom sediments are considered as net [2].

\section{Results and Discussion}

Ecological and geochemical assessment of bottom sediments have been made on the basis of calculated coefficients Co.

The results of the comparative analysis for heavy metals in bottom sediments are presented in Table 1.

Table 1. Calculated coefficients of heavy metals and arsenic in bottom sediments.

\begin{tabular}{|c|c|c|c|c|c|c|c|}
\hline \multirow{3}{*}{$\begin{array}{c}\text { Sample } \\
\text { points }\end{array}$} & $\begin{array}{l}\text { Calculated } \\
\text { coefficients }\end{array}$ & $\mathbf{C u}$ & $\mathbf{N i}$ & $\mathbf{P b}$ & $\mathbf{Z n}$ & $\mathrm{Cr}$ & As \\
\hline & Clarke, \% & 0.0047 & 0.0058 & 0.0016 & 0.0083 & 0.0083 & 0.00017 \\
\hline & $A P C_{0}$ & 0.0035 & 0.0035 & 0.0085 & 0.014 & 0.01 & 0.0029 \\
\hline \multirow{2}{*}{$\begin{array}{c}\text { Point 1 } \\
(2018)\end{array}$} & $C C$ & $<0.1$ & 0.2 & 0.7 & 0.3 & 0.7 & 9.4 \\
\hline & $\mathrm{Co}$ & $<0.1$ & 0.3 & 0.1 & 0.2 & 0.6 & 0.6 \\
\hline \multirow{2}{*}{$\begin{array}{c}\text { Point } 2 \\
(2016 / \\
2018)\end{array}$} & $C C$ & $0.2 /<0.1$ & $0.2 / 0.2$ & $\underline{\underline{\mathbf{1 . 1}} / 0.6}$ & $0.6 / 0.4$ & $0.4 / 0.6$ & $\underline{18.8} / \underline{16.5}$ \\
\hline & Co & $0.3 /<0.1$ & $0.4 / 0.4$ & $0.2 / 0.1$ & $0.4 / 0.2$ & $0.3 / 0.5$ & $1.1 / 0.9$ \\
\hline \multirow{2}{*}{$\begin{array}{c}\text { Point 3 } \\
(2016 / \\
2018)\end{array}$} & $C C$ & $0.2 /<0.1$ & $0.4 / 0.1$ & $0.8 / 0.6$ & $0.7 / 0.4$ & $0.7 / 0.6$ & $19.4 / 14.1$ \\
\hline & Co & $0.3 /<0.1$ & $0.6 / 0.2$ & $0.2 / 0.1$ & $0.4 / 0.2$ & $0.6 / 0.5$ & $\underline{\mathbf{1 . 1}} / 0.8$ \\
\hline \multirow{2}{*}{$\begin{array}{c}\text { Point 4 } \\
(2016)\end{array}$} & $C C$ & 0.4 & 0.2 & 0.8 & 0.8 & 0.8 & $\underline{10.0}$ \\
\hline & Co & 0.5 & 0.4 & 0.1 & 0.5 & 0.6 & $\overline{0.6}$ \\
\hline \multirow{2}{*}{$\begin{array}{c}\text { Point } 5 \\
(2018)\end{array}$} & $C C$ & 0.2 & 0.1 & 0.6 & 0.7 & 0.5 & 2.9 \\
\hline & $\mathrm{Co}$ & 0.3 & 0.2 & 0.1 & 0.4 & 0.4 & 0.2 \\
\hline \multirow{2}{*}{$\begin{array}{c}\text { Point 6 } \\
(2016 / \\
2018)\end{array}$} & $C C$ & $0.4 / 0.3$ & $0.1 / 0.2$ & $0.8 / 0.5$ & $0.8 / 0.6$ & $0.8 / 0.5$ & $\underline{4.7} / \underline{5.3}$ \\
\hline & Co & $0.5 / 0.4$ & $0.2 / 0.3$ & $0.1 / 0.1$ & $0.5 / 0.4$ & $0.6 / 0.4$ & $0.3 / 0.3$ \\
\hline \multirow{2}{*}{$\begin{array}{c}\text { Point } 7 \\
(2016 / \\
2018) \\
\end{array}$} & $C C$ & $0.6 / 0.6$ & $0.2 / 0.7$ & $0.4 / 0.8$ & $0.8 / 0.9$ & $0.6 / 0.9$ & $\underline{4.7} / \underline{22.4}$ \\
\hline & Co & $0.8 / 0.8$ & $0.3 / \underline{\mathbf{1 . 1}}$ & $0.1 / 0.2$ & $0.5 / 0.6$ & $0.5 / 0.8$ & $0.3 / \underline{\mathbf{1 . 3}}$ \\
\hline \multirow{2}{*}{$\begin{array}{c}\text { Point 8 } \\
(2016 / \\
2018) \\
\end{array}$} & $C C$ & $\underline{\underline{\mathbf{1 . 6}} /<0.1}$ & $1.0 / 0.6$ & $\underline{1.6} / \underline{1.3}$ & $\underline{\underline{1.2}} / 0.6$ & $\underline{\underline{\mathbf{1 . 1}} / 0.8}$ & 9.4 / $\underline{32.9}$ \\
\hline & Co & $\underline{\mathbf{2 . 1}} /<0.1$ & $\underline{\mathbf{1 . 7}} / 0.9$ & $0.3 / 0.2$ & $0.7 / 0.4$ & $0.9 / 0.6$ & $0.6 / \underline{\mathbf{1 . 9}}$ \\
\hline \multirow{2}{*}{$\begin{array}{c}\text { Point 9 } \\
\text { (2018) }\end{array}$} & $C C$ & $<0.1$ & 0.8 & $\underline{1.6}$ & 0.7 & 0.8 & $\underline{64.7}$ \\
\hline & Co & $<0.1$ & 1.4 & $\overline{0.3}$ & 0.4 & 0.7 & $\underline{\underline{3.8}}$ \\
\hline
\end{tabular}

Notes: The concentrations of elements above clarke/APC $\mathrm{A}_{0}$ are in bold; $C C$ is a concentration clarke, a ratio of chemical element content in bottom sediments to the clarke of this element; Co coefficient is a ratio of chemical element content in bottom sediments to $\mathrm{APC}_{0}$ of this element. 
The table shows the calculated coefficients for the study period 2016 and 2018. At some points were sampled only one year due to technical capacity. However, data at points $2,3,6,7$ and 8 provide an estimate of the change in heavy metal content over a period of 2 years.

Concentration clarke values of HM and arsenic show that local geochemical features of bottom sediments are characterized by excessive arsenic concentrations. CC values of arsenic exceed from 2.9 to 64.7. Moreover, the excess concentration of this element gradually increases from the Point 5 (the territory of the reserve) to the periphery - large bays that are not part of the reserve (Points 1, 2, 3 and 9). Temporary variations in arsenic content in bottom sediments are noted: at points 7 and 8 there is a significant increase in the concentration of this element, at point 6 - CC increases slightly from 4.7 to 5.3. Further along the coast in a northeasterly direction, arsenic content in the bottom sediments has decreased over a period of 2 years. In its turn, when comparing arsenic with $\mathrm{APC}_{0}$, the excess relatively to limit values was found only at point 9 (3.8 times), which is not included in the reserve's water area. According to the calculated indicators it can be concluded that locally in the area under consideration the maximum CC and Co values for arsenic were found at point 9 (Lis'ya Bay). It is the most visited recreational, tourist area, not belonging to the reserve, among all other sampling points. The high content of arsenic in bottom sediments can also be explained by local geochemical features.

In points 2, 8 and 9 an increase in lead concentration (CC value not exceeding 1.6) in bottom sediments has been noted. And the lead content decreased by 2018. Accumulation of copper, nickel, zinc and chromium in the bottom sediments have been observed locally in points 7,8 , and 9 with a tendency to decrease the content of these elements in the bottom sediments, because the calculated indicators generally decreased over 2 years. At the other points the excess of clarke for the lithosphere and the limit value of $\mathrm{APC}_{0}$ have been not observed in any of the points, there is it has been noted the dispersion of these elements compared with their average content in the Earth's crust.

As part of the assessment of bottom sediments using the methodology described in [7] it has been calculated Zc. The values of the $\mathrm{Zc}$ level of bottom sediments have been established for the values exceeding $\mathrm{APC}_{0}$ for each year under review. The final $\mathrm{Zc}$ values are presented in Table 2 .

Table 2. Bottom sediment assessment [7]

\begin{tabular}{|c|c|c|c|}
\hline Sample points & $\begin{array}{c}\text { Zc of estimated } \\
\text { elements } \\
(\mathbf{2 0 1 6} / \mathbf{2 0 1 8})\end{array}$ & $\begin{array}{c}\text { Level of HM } \\
\text { content in } \\
\text { bottom } \\
\text { sediments }\end{array}$ & $\begin{array}{c}\text { Level of HM content in } \\
\text { water }\end{array}$ \\
\hline Point $3(2016$ y.) & 0.1 & low level & \multirow{2}{*}{ weakly raised level } \\
\hline Point $7(2018$ y. $)$ & 1.4 & low level & \\
\hline $\begin{array}{c}\text { Point } 8 \\
(2016 / 2018 \text { y. })\end{array}$ & $2.8 / 0.9$ & low level & \\
\hline Point $9(2018$ y.) & 4.2 & low level & \\
\hline
\end{tabular}

In terms of Zc for heavy metals, bottom sediments have a low level of content, and in the aquatic environment their content is assessed as weakly raised in 2016 and 2018.

\section{Conclusions}

The geochemical feature of the reserve's territory adjacent to the water area led to the accumulation of a number of heavy metals in the surface parts of the bottom sediments. The research have shown that the levels of heavy metals in the bottom sediments of the Karadag reserve are weak and are not associated with anthropogenic influence. 
In accordance with the method adopted in the work using Clarks and limit value of $\mathrm{APC}_{0}$, the content of heavy metals in the water has weakly raised level.

Such observations will be continued in the future in order to monitor and evaluate the natural potential of the territory, in order to identify the natural background values of the concentration of heavy metals in bottom sediments. But for such purposes a longer observation period is needed.

In this instance, a clearer correlation of the source of elements entering the water from the land will be traced. And one of the most important topic to study in the future is the possibility of evaluating surface deposits in the land-sea complex.

The study was made as part of the IBSS research (registration number: AAAA-A19-119061-1900819).

\section{References}

1. GOST 17.1.5.01-80 Nature protection. Hydrosphere. General requirements for sampling bottom sediments of water bodies for contamination analysis

2. Regional standard: Standards and criteria for assessing the contamination of bottom sediments in water bodies in St. Petersburg

3. R.V. Galiulin, R.A. Galiulina, Water: chemistry and ecology, 3-8 (2011)

4. V.E. Sokolov, Reserves of USSR. Karadag reserve, 226-241 (1987)

5. Klyukin A.A., Exogeodynamics of Crimea, 320 (2007)

6. A.I. Perelman, Geochemistry, 531 (1989)

7. I.I. Kosinova, T.V. Sokolova, VSU Bulletin. Series: Geology, 3, 113-121 (2015)

8. Warmer H., van Dokkum R, Water pollution control in the Netherlands. Policy and practice, 77 (RIZA, Lelystad, 2001). 